\title{
“Wrap It Up!” Discourse on Condom Use among African American College-Attending Men in the Southern US
}

\author{
Taylor Coleman ${ }^{1}$, Kenneth Gabriel ${ }^{2}$, Nicole Coleman ${ }^{1}$, Chakema Carmack ${ }^{1}$ \\ ${ }^{1}$ Psychological, Health, \& Learning Sciences Department, University of Houston, Houston, Texas, USA \\ ${ }^{2}$ Department of Health Communications, Jack J. Valenti School of Communication, University of Houston, Houston, Texas, USA \\ Email: ccarmack@central.uh.edu
}

How to cite this paper: Coleman, T., Gabriel, K., Coleman, N. and Carmack, C. (2018) “Wrap It Up!” Discourse on Condom Use among African American College-Attending Men in the Southern US. Open Journal of Social Sciences, 6, 111-126. https://doi.org/10.4236/jss.2018.612011

Received: November 10, 2018

Accepted: December 17, 2018

Published: December 20, 2018

Copyright $\odot 2018$ by authors and Scientific Research Publishing Inc. This work is licensed under the Creative Commons Attribution International License (CC BY 4.0).

http://creativecommons.org/licenses/by/4.0/

\begin{abstract}
Historically Black colleges and universities (HBCUs) are in a unique position to impact the incidence and awareness of sexually transmitted infections (STIs) and prevention on campus. HBCUs, particularly in the South, have been associated with disproportionately high rates of STIs. In light of sexual activity, condom use remains the most effective prevention strategy. We sought to explore the facilitators of male condom use among college-attending African American men in the South. Six focus groups $(\mathrm{N}=36)$ were conducted and analyzed. Thematic analysis resulted in eight emergent themes: Condom Use Avoids Pregnancy, STIs as Undesirable, Assertive Pro-Condom Partners, Condom Use Endorsements, Condom Non-use: Feelings and Timing, Condom Availability, Condom Use versus PrEP and Curability, and HIV Promotion on Campus. Recommendations include: gaining college leadership for STI and condom use awareness, incorporating peer education in prevention efforts, and capitalizing upon the intrapersonal benefits of condom use.
\end{abstract}

\section{Keywords}

Sexually Transmitted Infections, HIV/AIDS, Thematic Analysis, Condom Use

\section{Introduction}

College and university campuses confer a community that fosters academic learning, professional skill-building, and social learning that reach beyond the classroom. Students belonging to a particular college develop a perceived sense 
of community where their social environment encourages common social interests [1]. Most college students report multiple sexually transmitted infection (STI) risk-related behaviors, such as multiple partners, unprotected sex, and co-morbid drug or alcohol use and sexual encounters [2] [3] [4]. As such, colleges and universities are in a unique position to impact the incidence and awareness of STIs and STI prevention among young adults on campus through a shared sense of importance and resource availability.

STI incidence disparities have been reported among African American college students, in particular. African American college students report significantly more sex partners, characterized by having sex with four or more persons within the past year, than their White counterparts $(12 \%$ vs. $8 \%, p<0.001)$ [5]. Among ten colleges and universities in Southern states, a STI prevalence of $11 \%$ for African American students, compared to $1 \%$ for White students, was estimated [6]. Historically Black colleges and universities (HBCUs), in particular, may incur high rates of disease burden as well. Although students attending HBCUs have reported less STI risk-related behavior, they experience greater STI burden [7] [8] and may serve as a "bridge" for high- and low-risk communities [9]. African Americans, in general, tend to restrict their sexual networks within their race, more so than other racial groups; thereby compounding the probability of STI contraction in the African American community [10].

African American men account for approximately one-third of all diagnosed HIV incidences. In the US, African American males make up 63\% of all heterosexual transmitted HIV incidences [11]. While men who have sex with men (MSM) carry the heaviest burden of HIV, there remains a disparity among heterosexual men in the South regarding HIV acquisition. In 2014, there were approximately 1500 new cases of HIV among heterosexual African American men in the Southern states alone [11]. This is over three times higher than the frequency of heterosexual White and Latino men and women in the South. Likewise, other STIs merit attention in the disparities among African Americans. African American account for $69 \%$ of gonorrhea and 47\% of syphilis incidences; and the rate of chlamydia is seven times higher for African American men than for their Caucasian counterparts. While targeted efforts tailored for MSM are certainly worthy public health endeavors, these rates nevertheless demonstrate the need for utilizing protection to guard against STIs among young African American men, irrespective of their sexual orientation. Because condom use remains the most effective method of STI prevention in light of sexual behavior, efforts to understand the facilitators of condom use identifying areas for STI/HIV prevention on HBCU campuses remain important.

\subsection{Theoretical Framework}

The integrated model of behavioral prediction (IM) is a popular health behavior theory that offers a rationale for engaging in a particular behavior [12]. Predecessors to the theory, the theory of reasoned action [13] and the theory of planned behavior [14], have been useful in preventative health behaviors such 
condom use and decreased STI risk [15] [16]. The IM posits that intention is the ultimate antecedent of behavior, given that an individual has the skill to perform the particular behavior and there are no environmental constraints to performing the behavior. The intention construct is composed of attitudes (a positive or negative valuation of the behavior), subjective norms (the importance of important others regarding the behavior), and self-efficacy (the situation-specific ability to carry out a particular behavior).

The IM constructs have been utilized in previous research involving sexual risk behaviors [17] [18]. Farmer and Masten [19] used a validated scale of sexual risk behaviors and found that attitudes about condoms, self-efficacy barriers to condom use, and communicating about sexual encounters significantly predicted condom use among an ethnic diverse sample of college students $(\mathrm{N}=$ 665). Of note, these associations were found among both non-virgin and virgin participants, separately. The IM constructs may also operate with differing weights in their influence on condom use among the genders. Carmack, Lewis, and Roncancio [20] found that the IM constructs exhibited greater predictability to use condoms among adolescent males than adolescent females in a sample of 446 African American adolescents using a multi-group structural equation modeling analysis. Particularly for females it was hypothesized and confirmed that self-efficacy for condom use negotiation was a greater predictor of intentions to use condoms than self-efficacy toward condoms among a sample of 560 African American females $\left(M_{\text {age }}=20.6\right)$ [21]. Fear that their partner would not agree with condom use and subsequently leave or abuse them was an environmental factor that negatively affected their attitudes, subjective norms, and self-efficacy toward condom use. Thus, in accordance with the IM, it is also important that environmental factors do not impede performing the behavior, but rather foster the performance of health promoting behaviors. This notion brings relevancy to the social environment of the college campus as it relates to condom use.

\subsection{The Present Study}

Although previous studies have examined condom use and non-use among vulnerable populations, the present study fills an important gap in the literature by exploring condom use among African American college-aged men using an in-depth qualitative approach. An examination is warranted because 1) traditional college-aged men are included in the most vulnerable age range (ages 13 24) for HIV transmission, 2) African American men's rate of transmission is staggeringly higher than their racial male peers, especially in the South, and 3) the traditional campus communities of HBCUs are relatively contained with regard to social environment and a sense of belonging [16], making it a worthwhile entry point for increased HIV and STI awareness and prevention. Given this, the present study conducted a series of guided focus groups in order to understand the complex factors that facilitate or impede condom use among African American men on the college campus. Guided by the IM (attitudes, subjec- 
tive norms, self-efficacy, and campus environment), the overarching research question was, "What are the individual, social, and environmental facilitators of condom use among African American men attending college?" Findings may be useful for prevention programs, awareness, and intervention messaging on campus and offer insights for further investigation to college health research and practice professionals on HBCU campuses.

\section{Methods}

\subsection{Participants}

From July 2017 through September 2017, we conducted six focus groups with African American college-attending men. We recruited a convenience sample of participants from community centers, health fairs, and local organization meet-ups. Eligibility criteria included identifying as African American, 18 or older, speaking English as a primary language, and current college enrollment. Our sample consisted of 36 men enrolled in college at a HBCU in the Southern geography of the United States. Six focus groups were moderated by a trained moderator. For focus group sessions 1-6, the distribution of participants was 6 , $7,8,6,7$, and 4 , respectively.

\subsection{Procedure}

We conducted focus groups which allowed us to gain an understanding of condom use and STIs on the college campus. The conversational nature of focus groups allowed the participants to draw upon their own experiences in contribution (or contradiction) to one another [22]. All procedures were approved by the university's institutional review board. Participants were approached at various campus- and community-related events and given a brief oral description of the study. We explained the purpose of the study, eligibility criteria, scheduling of the focus group sessions, and future time commitment to participate. Those who were interested in participating were recruited for participation and contacted by email to choose a scheduled session.

Focus group sessions took place within a closed-door meeting room at a local university in the evenings. At the start of each session, participants were consented, informed that their identities would remain anonymous, and explained the rules of the focus group session (-namely to be respectful during conversation, to keep all conversation that took place during the session confidential, and explained that they could leave at any time for any reason at their discretion). Upon agreement, the participants completed a brief demographic survey (age, classification, sexual orientation, committed relationship status). The focus groups were moderated and audio-recorded by a male member of the research team. The moderator also took notes during each focus group. The focus groups session lengths ranged from 60 - 90 minutes. Participants received no compensation for participation, and informed that they could contact the research team about this research at any time. Following the sixth focus group, the research 
team felt that saturation had been meet, as the fifth and sixth focus group members had similar sentiments, opinions, and experiences as the previous focus group participants.

\subsection{Measures}

Based on the overarching research question ("What are the individual, social, and environmental facilitators of condom use among African American men attending college?"), a guided focus group script was developed with ten specific questions for discussion that can be found in Table 1.

\subsection{Analysis}

Thematic analysis was used to analyze the response patterns, develop themes, and interpret various aspects of the themes. We applied an inductive analysis approach to analyzing the data. This means that even though our focus group guide was theoretical in nature, we coded the data without attempting to "fit" the data into the theoretical framework. We were interested to see if the data (i.e. focus group discussions) would yield patterns that were consistent with the IM theory; however, we were just as interested to see if other themes unrelated to the IM would emerge from the data.

The researcher initially listened to the audio recordings of each focus group several times and read through the transcripts of data carefully. All five focus group sessions were transcribed verbatim by a research assistant and verified by the primary researcher by conducting a read-through of the transcripts along with the audio. The thematic analysis of the data proceeded in six phases identified by Braun and Clarke's [23] detailed guide for using thematic analysis. Phase one included familiarization to the data, in which the researcher carefully read through the focus group transcriptions several times and made notes about impressions that stood out. A list of 46 potential codes emerged. Phase two included the formal coding process. The initial codes were then compiled on a spreadsheet with matrices in which participant's responses/quotes were entered into the rows and the codes were entered in adjacent columns at the top [24]. Four independent researchers/research assistants selectively coded each piece of dialogue by marking the cells under each code as appropriate. The coding team consisted of two professional researchers in the field and two psychology graduate research assistants. All coding discrepancies were discussed and resolved unanimously. A final spreadsheet of all pieces of dialogue, their associated codes, and counts was formulated and distributed among the research team.

During phase three, which was to search for themes, all coded excerpts (and surrounding/contextual dialogue) were organized by code. Initial themes were developed by identifying codes that could be combined into a central concept, or theme. We then created a thematic visual that identified the overarching theme, codes that it subsumed, and all pieces of related dialogue. Ten initial themes were conceptualized and named. Phase four involved reviewing the ten initial themes. Upon examination of the thematic visual, the research team discussed 
Table 1. Focus group questions and theoretical construct.

\begin{tabular}{ll}
\hline $\begin{array}{l}\text { attitudes, subjective norms, } \\
\text { self-efficacy, environment }\end{array}$ & $\begin{array}{l}\text { Among you and your friends here on campus, what do you think } \\
\text { are some of the factors that play a role in a guy's decision to use } \\
\text { condoms? }\end{array}$ \\
\hline attitudes & $\begin{array}{l}\text { How important is condom use when it comes to having sex with } \\
\text { your partner? }\end{array}$ \\
subjective norms & $\begin{array}{l}\text { Has anyone important to you in your family talked to you about } \\
\text { using condoms in college? }\end{array}$ \\
self-efficacy & $\begin{array}{l}\text { How easy is it to get condoms? } \\
\text { subjective norms, self-efficacy }\end{array}$ \\
Would you be OK if your partner did not want to use \\
condoms? ... Would you not use them? \\
environment & $\begin{array}{l}\text { Does risky behavior, like drinking or drugs, play a part in condom } \\
\text { use around campus? }\end{array}$ \\
attitudes, environment & $\begin{array}{l}\text { How big of a problem do you think STIs are on this campus? ... } \\
\text { How do you think this affects condom use? }\end{array}$ \\
attitudes, environment & $\begin{array}{l}\text { How big of a problem do you think HIV is for young Black adults } \\
\text { in general? ... How do you think this affects condom use? }\end{array}$ \\
environment & $\begin{array}{l}\text { What are some things that would increase condom use around } \\
\text { campus? }\end{array}$ \\
\hline
\end{tabular}

themes and identified two themes that would be better combined into another theme, due to theme nine's similarity of concept to another theme, and theme ten's lack of sufficient data to be considered a central theme on its own. The excerpts from theme with insufficient data were already subsumed by other central themes. Thus, the final set of central themes included a total of eight themes.

Phase five involved refining and defining the themes. Upon refinement of the thematic visual, the research team carefully examined the central themes and adjacent dialogue, keeping in mind 1) whether they accurately reflected the meanings of the focus group discussions, 2) whether the themes were meaningfully distinct from one another, and 3) whether the theme name was a clear and concise representation of what the theme attempted to encapsulate. Sub-themes, where identified, were also explored within this phase. Phase six included writing up the results in a coherent and vivid story that captured the essence of what the young men conveyed via the focus group discussions. Particularly vivid or straightforward dialogues were also chosen by the research team as examples of the theme in this phase as well. Throughout the thematic analysis process, particularly in phases 1, 3, and 5, Atlas.ti 7 qualitative software was utilized for accuracy and efficiency as appropriate.

\section{Results}

Demographic characteristics for the sample (race, age, sexual orientation, committed relationship status) are reported in Table 2 . The majority of the participants $(97 \% ; N=35)$ originated from Southern US states that included Louisiana, Texas, Mississippi, and Georgia. Three percent $(\mathrm{N}=1)$ was from the Northeast (N.E. Virginia). 
Table 2. Sample demographics.

\begin{tabular}{lc}
\hline \multicolumn{1}{c}{ Age } & $20.5(1.4)^{\mathrm{a}}$ \\
\hline Race/Ethnicity & \\
Black & $100(36)$ \\
Multi-Racial $^{+}$ & $5.6(2)$ \\
Hispanic (Any Race) & $2.8(1)$ \\
Classification & \\
Freshman & $19.4(7)$ \\
Sophomore & $41.7(15)$ \\
Junior & $33.3(12)$ \\
Senior & $5.6(2)$ \\
Sexual Orientation & \\
Heterosexual & $91.6(33)$ \\
Bi-Sexual & $5.6(2)$ \\
Unanswered & $2.8(1)$ \\
Committed Relationship Status & \\
Monogamous & $13.9(5)$ \\
Non-monogamous & $86.1(31)$
\end{tabular}

a. Participants were able to select multiple race-ethnicities. b. Sample consisted of $\mathrm{N}=2$ participants who reported African American and Caucasian race.

Data analysis resulted in eight themes in response to the overall research question regarding individual, social, and environmental facilitators of condom use among African American men in college: Condom Use Avoids Pregnancy, STIs as Undesirable, Assertive Pro-Condom Partners, Condom Use Endorsements, Condom Non-use: Feelings and Timing, Condom Availability, Condom Use versus PrEP and the Curability of STIs, and HIV Awareness and Promotion on Campus. An additional theme, Peer Educators, emerged as a secondary theme of HIV Awareness and Promotion on Campus. Age of participant is reported in parenthesis following specific dialogue examples.

\subsection{Theme 1: Condom Use Avoids Pregnancy}

All participants reported being either heterosexual or bi-sexual orientation men, and the avoidance of pregnancy was the most cited reason for condom use. Among the six focus groups $(\mathrm{N}=36), 20$ participants directly talked about how an unintended pregnancy could negatively affect them. Many of the participants had family members or friends who experienced teenage pregnancy, and some participants had female peers who have since dropped out of college due to unplanned pregnancy. In particular, participants cited their parents (usually fathers) for having straight-talk with them about getting a young woman pregnant and the lifestyle changes that accompany it.

- "I have too much to do than to get a girl pregnant. That's why I'm 'wrapping it up' every time." (Age, 19)

- "My Pops [Father] looked me straight in the eye and said, 'Dude, you think you man now? -Don't come back with any babies.' Cus real men take care of their responsibilities first." Moderator: "What do you think he meant by that?" Participant: "Well, just that real men have to provide for their families, 
you know. I mean, I got to get an education first and all." (Age, 18)

\subsection{Theme 2: STIs as Undesirable: "Catching Something"}

Among the focus groups, conversations surrounding STIs were participant-initiated and discussed as a factor influencing condom use. Although the length and breadth of discussions involving STIs were not as substantial as the discussions surrounding the avoidance of unwanted pregnancies, the majority of the participants either spoke about or indirectly agreed (e.g. head nods, supportive exclamations, etc.) that "catching something" was a motivator for condom use. Participants also discussed how they are old enough to know that just because a sexual partner takes care of herself/himself physically and exhibits "cleanliness," it does not mean they are insusceptible to STIs.

- "Well I'm not having sex without protection because it's too much stuff out there. I'm not going to spend my time in the clinic trying to get shots and take pills for catching something. ... But then there is stuff you can't get rid of; and that's scary. Nah, it feels just as good [with a condom] [rather] than to be going through all that." (Age, 20)

- "I don't want to sit here and say that every time I had sex that I used a condom. But when I think about it a week or two later, I'm lucky not to have caught anything." (Age, 21)

\subsection{Theme 3: Assertive Pro-Condom Partners}

Many participants made it clear that (-in consensual heterosexual coitus) women have all the power when it comes to condom use. Many of the participants reported that if a woman is adamant about using a condom, then men would usually comply. Even with light resistance and persuasion tactics (e.g. male partner not having a condom in the moment or comments about not liking them), these men were likely to comply with a woman who has a condom present during sex initiation. In addition, a bi-sexual participant (who self-disclosed his sexual orientation to the group) explained that it is not uncommon for the same to be true within gay male sexual partnerships.

- "Honestly, the girl is the one really in control when it comes to condom use. He's going to do what she wants to get what he wants, simple as that." (Age, 22)

- "I've had a girl ask [about using a condom], and I'm like I don't have one on me. She'll be like 'hold up wait, I do,' and pull one right out." (Age, 23)

- "Well I'm bi-; some of you already know that. But anyway, it's the same for guy-on-guy. I say the same thing with guys and girls, 'no glove, no love.' ... So somebody better come up with a condom from somewhere." (Age, 20)

\subsection{Theme 4: Condom Non-Use: Feelings and Timing}

Focused questions were derived to gain insight into the major facilitators of condom use among men; however, conversations emerged as to why a college 
guy would not like to use condoms. The answers did not vary widely. Some reported that many men like the way skin-on-skin feels, and many others reported that their female partners did not want to use condoms over time. Participants discussed how a sexual relationship, though non-committal, may start off with condom use, but becomes less frequent as time progresses and the sexual relationship continues. Both parties may become comfortable with one another and trust that the other is "safe." Although this particular issue was discussed in varying degrees among five out of six of the focus groups, there was only one man who indicated that he and his girlfriend got tested for HIV together.

- "Me and my girlfriend have been together since freshman year. We don't have to use condoms, and we just like the way it feels without." (Age, 20)

- "Some things make a woman not want to use a condom. Like if she's been with the guy a long time and she probably trusts him even if she's not his main girl." (Age, 21)

\subsection{Theme 5: Condom Use Endorsements}

Parents, particularly fathers and other familial males, played a significant role in conveying the importance of condom use for these college men. Participants recalled discussions about condoms with their parents or other family members that influenced their positions on condom use while in college. Mothers and friends were less mentioned in their role of conveying condom use to the young men. In some cases, older brothers, cousins, or uncles were instrumental in communicating their intentions for the young men to use condoms.

- "Even before I was having sex, my dad would ask me if I had one [condom] on the way out the door. I wasn't even having sex then, but I already knew to get one before I did." (Age, 19)

- "My brother lives in [campus residence hall]. He'll come over to my room to hang out and then just drop one [condom] off on the dresser when he leaves, and says 'Just in case you need that!' I keep my own, but I know that his way of saying I better be using them." (Age, 20)

\subsection{Theme 6: Condom Availability}

Some participants discussed the self-efficacy and resource availability regarding condom use. Friends played a major role in the availability of condoms. It is usually easy to find a condom from other friends on campus. Many participants discussed sharing condoms among their male friends, whether as the recipient or the one who provided a condom for a friend. On-campus and off-campus venues that cater to the college population have free condoms for students. Availability of condoms in the campus environment was not a perceived barrier to condom use.

- "You see them in the ball rooms, in a bucket in the bathrooms. They have them everywhere. They have them at the club in a bucket. They put them out at the bar in different clubs. Just get them out of a truck stop bathroom. You 
can get them anywhere." (Age, 21)

- "In a week you spend more money on food. Just take $\$ 5, \$ 6$, or $\$ 10$ and go get a pack of condoms." (Age, 21)

- "... Or just ask one of your boys. Somebody has a condom that you can have." (Age, 20)

\subsection{Theme 7: Condom Use versus PrEP and the Curability of STIS}

When asked about whether they thought HIV and other STIs were a problem on campus and in the Black community, the participants were aware of HIV and other STIs as a geographic (campus) concern, but not so much as a personal health concern for them individually. "Catching something" (Theme 2) was one of the main motivations for condom use. However, the gravity of HIV and other STIs seemed to be marred by the notion that many STIs are curable. There were also misconceptions about PrEP, used in high-risk populations to prevent spread of HIV in the body. Overall, participants had the notion that STIs are not desirable, but the ease of campus healthcare services made it less of a concern for them.

- "PrEP is like a vaccine, right? ... You just take your pills and you don't even have to worry about it [HIV]." (Age, 19)

- "I recently heard on NPR [National Public Radio] that they're close to a cure for HIV. Nobody's going to be worried about catching anything after that." (Age, 19)

- "People know stuff [STIs] is out there. But nowadays, you can just go to the clinic, right here on campus, and get a shot and take your pills. People think getting chlamydia is like catching a cold!" (Age, 21)

\subsection{Theme 8: STI and Condom Use Awareness and Promotion on Campus}

The participants believed that HIV awareness is important, yet understated regarding official campus-wide awareness. Participants expressed that they were able to openly discuss facts and statistics among their individual social groups. However, some participants expressed disappointment that there was not more top-down awareness activities on campus from their campus leadership and health clinics. Participants were aware and familiar with other campus health initiatives (e.g. physical fitness, stress reduction), but felt that sexual health was not as widely promoted as general health and well-being campaigns.

- “There just isn't enough top-down support for awareness. The student organizations and some frats may have something going on and whatnot, but if the president or chancellor got behind some of the issues, I think it would make a difference." (Age, 23)

- "If there were some events to really bring that message home, other than us just sitting around talking about it, that would be good. More people would protect themselves if they knew the real facts." (Age, 20)

- "I mean, how cool would it be to see Dr. [the Chancellor] outside in the quad 
passing out condoms." (Age, 20)

Peer education emerged as a sub-theme of theme eight in the thematic analysis process. Peer education was mentioned in four separate focus groups in relation to STI promotion and condom use advocacy on campus. Some participants were aware of peer educators that are charged with mentorship in college success, as well as college health. Among the focus groups, three of the participants were current peer educators.

- Moderator: "You mentioned peer educator. So what exactly is a peer educator?" Participant: "It's a volunteer program-mostly seniors, that give awareness to HIV - all STD's, really. We hold workshops and try to sponsor other activities that mainly tell students about campus life, dating and relationships, and knowledge on HIV. There's not very many of us right now, and we try to tell who we can, but if we had more visibility, that would be good." (Age, 22)

- "I'm a peer educator here. I try to give awareness to the situation whenever I can. Some of the freshman I tutor, I'm like 'yeah, be sure to wrap it up, though [i.e. use a condom].' They need to hear that from us." (Age, 20)

From the data obtained from the focus groups, postulated relationships were ascertained by the research team to aid in further investigation. Table 3 summarizes the postulated relationships observed from the eight themes. According to the participants, factors that would increase or decrease condom use were specified. In addition, there was one factor that seemed to neither increase nor decrease condom use base on the discourse data. The specific IM construct is listed for each factor.

Table 3. Postulated relationships associated with condom use among college-attending african american men.

\begin{tabular}{|c|c|c|}
\hline Postulated Relationship & Factor & IM Construct \\
\hline \multirow{9}{*}{ Would increase condom use } & Fear of unintended pregnancy & Attitude (Instrumental) \\
\hline & STI Vulnerability & \\
\hline & Sex Partners' Assertion of Condom & Attitude (Instrumental) \\
\hline & Use & Subjective Norm \\
\hline & Father Figures' Endorsement of & \\
\hline & Condom Use & Subjective Norm \\
\hline & Peer Education & \\
\hline & Campus Leadership Advocacy for ST & I Subjective Norm \\
\hline & Prevention & Environment \\
\hline \multirow{6}{*}{ Would decrease condom use } & Perceptions of a "Committed" & Attitude (Affective) \\
\hline & Relationship & \\
\hline & Time and Familiarity with Sexual & Attitude (Affective) \\
\hline & Partner & \\
\hline & Perception of PrEP & Self-Efficacy \\
\hline & Perceived “Curability” of STIs & Self-Efficacy \\
\hline $\begin{array}{l}\text { May increase or decrease } \\
\text { condom use }\end{array}$ & $\begin{array}{l}\text { Sex Partner's Condom Use } \\
\text { Preferences }\end{array}$ & Subjective Norm \\
\hline $\begin{array}{l}\text { Neither Increases or } \\
\text { decreases condom use }\end{array}$ & Condom use availability & Self-Efficacy \\
\hline
\end{tabular}




\section{Discussion}

Although academics are the priority of colleges and universities, they are also places where young adults are exploring their relationships and intimate partner freedoms. The goal of the present study was to gain an understanding of the interpersonal, intrapersonal, and socio-environmental facilitators of condom use among African American men on the college campus. Guided by the IM that purports attitudes, subjective norms, self-efficacy, and environment play a pertinent role in behavior, eight themes emerged. Five themes, "Condom Use Avoids Pregnancy," "STIs as Undesirable: 'Catching Something,", "Assertive Pro-Condom Partners," "Condom Use Endorsements," and "HIV Awareness and Promotion on Campus" emerged, providing attitudes about condoms, subjective norms, self-efficacy, and socio-environmental factors that favored condom use. Two themes, "Condom Non-use: Feelings and Timing," and "Condom Use versus PrEP and the Curability of STIs" emerged, providing attitudes and subjective norms that were in contradiction to condom use; and one theme, "Condom Availability" was deemed neutral regarding personal condom use among the young men.

These African American young adult males felt strongly about the use of condoms in order to prevent unintended pregnancy. Discussions on pregnancy prevention were more prevalent and in-depth than discussions involving the efficacy of condoms to prevent HIV or other STIs. There seemed to be a false sense of security about condom use, depending on whether or not one is in a monogamous relationship, which is consistent with previous research [25] [26]. However, serial monogamy, which is the engagement of successive monogamous relationships, may be a sexual health hazard when condoms are not used, even if a sexual partnership is assumed to be monogamous. Condom use is significantly lower among these individuals; and there is an increased probability for STI transmission when the gap between a current and successive sexual partner is shorter than an unbeknownst infectious period [27].

For the participants in the current study, although they were knowledgeable about condom use for STI prevention, there was a lack of understanding regarding the vulnerability of not using condoms $100 \%$ of the time. For example, there was a 21 year old participant who referenced that he does not use condoms all the time, but when contemplating it a week later, he believed he was "lucky" not to have acquired an STI. This is troublesome since many STIs do not present with symptoms until six to ten weeks later. A surprising finding was that there was less dissonance for contracting an STI depending on its curability. The perceived curability of a disease may present a non-adherence for preventative measures. This may stem from miseducation and misinformation on the part of young individuals who do not critically research or seek additional sources about preventative medications or treatments such as PrEP. The themes revealed a juxtaposition regarding unwanted STIs as a facilitator of condom use, yet a prevailing notion that almost all STIs are curable or manageable with medicine. This is likewise alarming, due to the fact that STIs pose serious biological com- 
plications and can lead to impediments of the reproductive organs, whether they are treated, curable, or not. Moreover, this misconstrued efficacy may have serious public health concerns involving antibiotic resistant strains of STIs, for instance.

Theme eight, "STI and Condom Use Awareness and Promotion on Campus," suggested that there be more support from more "influential" and powerful voices such as the president or chancellor of a university on the topic of STIs. On-campus programs are imperative to aid in promoting accurate knowledge and establishing on-going education, not only from the academic perspective, but also in the socio-cultural realm through connecting individuals in a shared wellness. Connecting individuals may be facilitated through peer education. Peer education on STIs and condom use has been found to have positive impacts on program efficacy and behavior change [28].

\subsection{Implications}

Health facilitators on the college campus, such as nurses and peer educators, are likely to meet and attend to emerging adults in college whose daily lives and scholastic activities become interrupted by HIV and other STIs. Health educators and practitioners may inform students on a variety of ways to keep themselves free from STI impacts, such as abstinence (100\% effective), condom use (99\% effective), and more recently for "at-risk" sub-populations, pre-exposure prophylaxis (PrEP) (90\% lowered risk of HIV only).

This study provides insights into intervention aspects to those researching, educating, and advocating for community and campus programs that address sexual health disparities and behavior change through increased condom use. Based on the current findings, it is recommended that prevention programs, interventions, or risk-reduction campaigns discuss the "curable" STIs and emphasize how contracting a treatable STI still has negative or detrimental consequences to one's health and society overall. "Luck" should not play an active part in the prevention of STIs. It is also recommended that STI prevention programs aimed at increasing condom use include pregnancy prevention as a highlighted advantage of using condoms consistently and correctly. Additionally, students would benefit from seeing their college leaders or well-respected professors supporting and endorsing STI prevention efforts. Lastly, incorporating peer educators, which can be trained by campus nurses or other health practitioners, is recommended in order to capitalize upon the shared sense of community among the students on college campuses. The introduction of peer educators as cultural brokers may aid in providing a better understanding of condom use and how it affects the individual's likelihood of STI exposure. Peer education efforts should also incorporate top-down college leadership endorsement.

\subsection{Limitations and Future Research}

Although saturation of the data was met, generalizability cannot be assumed due 
to convenience sampling and sample size. Thus, the findings would require replication to confirm the posited relationships. Although sexual orientation was not an eligibility criterion, selection bias may have impeded openly gay or bi-sexual men from participation.

In addition to replicating the findings among non-HBCU college-attending men, future research should also examine condom use, STIs, and the college-campus environment among gay and bi-sexual African American men. Throughout the focus groups conducted in the present study, HIV and STI testing was not mentioned in the context of university resources or testing drives. Future research might want to specifically inquire about whether testing would be feasible or acceptable to initiate or increase on campus. It is also interesting to explore how African American females would contextualize issues involving condom use and the prevention of STIs on HBCU campuses. Comparing and contrasting the findings from variant representative sub-groups on campus may lend itself to new intervention insights.

\section{Conclusions}

Within the sense of community that college students develop, it is pertinent to establish a culture of sexually healthy behaviors. It is the intention that those behaviors are not only maintained and carried on into adulthood, but also impressed onto one other within a social group at present. Thus, colleges and universities can impact safer sexual behaviors and norms.

The qualitative nature of the present study allowed for the research team to let the data "speak to us." Our goal was to understand exactly what notions, attitudes, or ideas, could be capitalized upon by health practitioners on the college campus in order to convince, encourage, or sustain consistent condom use among young African American men in college. The themes that were established in the current study revealed many aspects that set a baseline for future strategies in the prevention of STIs and the promotion of condom use; particularly among HBCU college-attending African American men.

\section{Conflicts of Interest}

The authors declare no conflicts of interest regarding the publication of this paper.

\section{References}

[1] Lounsbury, J.W. and DeNeui, D. (1996) Collegiate Psychological Sense of Community in Relation to Size of College/University and Extroversion. Journal of Community Psychology, 24, 381-394. https://doi.org/10.1002/(SICI)1520-6629(199610)24:4<381::AID-JCOP7>3.0.CO;2$\underline{\mathrm{X}}$

[2] Bazargan, M., Kelly, E.M., Stein, J.A., Husaini, B.A. and Bazargan, S.H. (2000) Correlates of HIV Risk-Taking Behaviors among African-American College Students: The Effect of HIV Knowledge, Motivation, and Behavioral Skills. Journal of the Na- 
tional Medical Association, 92, 391-404.

[3] Calloway, D.S., Long-White, D.N. and Corbin, D.E. (2014) Reducing the Risk of HIV/AIDS in African American College Students: An Exploratory Investigation of the Efficacy of a Peer Educator Approach. Health Promotion Practice, 15, 181-188. https://doi.org/10.1177/1524839913504757

[4] Poulson, R.L., Bradshaw, S.D., Huff, J.M., Peebles, L.L. and Hilton, D.B. (2008) Risky Sex Behaviors among African American College Students: The Influence of Alcohol, Marijuana, and Religiosity. North American Journal of Psychology, 10, 529-542.

[5] American College Health Association National College Health Assessment (2012) American College Health Association-National College Health Assessment II: Reference Group Executive Summary Spring 2012. American College Health Association, Hanover.

[6] James, A.B., Simpson, T.Y. and Chamberlain, W.A. (2008) Chlamydia Prevalence among College Students: Reproductive and Public Health Implications. Sexually Transmitted Diseases, 35, 529-532. https://doi.org/10.1097/OLQ.0b013e3181676697

[7] Buhi, E.R., Marhefka, S.L. and Hoban, M.T. (2010) The State of the Union: Sexual Health Disparities in a National Sample of US College Students. Journal of American College Health, 58, 337-346. https://doi.org/10.1080/07448480903501780

[8] Younge, S.N., Corneille, M.A., Lyde, M. and Cannady, J. (2013) The Paradox of risk: Historically Black College/University Students and Sexual Health. Journal of American College Health, 61, 254-262. https://doi.org/10.1080/07448481.2013.799480

[9] Hightow, L.B., MacDonald, P.D., Pilcher, C.D., Kaplan, A.H., Foust, E., Nguyen, T.Q. and Leone, P.A. (2015) The Unexpected Movement of the HIV Epidemic in the Southeastern United States: Transmission among College Students. Journal of Acquired Immune Deficiency Syndrome, 38, 531-537. https://doi.org/10.1097/01.qai.0000155037.10628.cb

[10] Centers for Disease Control and Prevention (2018) HIV among African Americans. https://www.cdc.gov/hiv/group/racialethnic/africanamericans/index.html

[11] Centers for Disease Control and Prevention (2016) HIV in the Southern States: CDC Issue Brief. https://www.cdc.gov/hiv/pdf/policies/cdc-hiv-in-the-south-issue-brief.pdf

[12] Fishbein, M. (2011) Review of Predicting and Changing Behavior: The Reasoned Action Approach. Psychology Press, Taylor \& Francis Group, New York.

[13] Ajzen, I. (1985) From Intentions to Actions: A Theory of Planned Behavior. In: Kuhl, J. and Beckman, J., Eds., Action-Control: From Cognition to Behavior, Springer, Heidelberg, 11-39. https://doi.org/10.1007/978-3-642-69746-3_2

[14] Ajzen, I. and Fishbein, M. (1975) A Bayesian Analysis of Attribution Processes. Psychological Bulletin, 82, 261-277. https://doi.org/10.1037/h0076477

[15] Carmack, C. and Lewis, R.K. (2009) Examining the Theory of Planned Behavior Applied to Condom Use: The Effect-Indicator vs. Causal-Indicator Models. Journal of Primary Prevention, 30, 659-676. https://doi.org/10.1007/s10935-009-0199-3

[16] Freeman, K. (2005) African Americans and College Choice: The Influence of Family and School. SUNY Press, Albany.

[17] Ajzen, I. (1991) The Theory of Planned Behavior. Organizational Behavior and Human Decision Processes, 50, 179-211. https://doi.org/10.1016/0749-5978(91)90020-T

[18] Godin, G. and Kok, G. (1996) The Theory of Planned Behavior: A Review of Its Ap- 
plications to Health-Related Behaviors. American Journal of Health Promotion, 11, 87-98. https://doi.org/10.4278/0890-1171-11.2.87

[19] Farmer, M.A. and Masten, C.M. (2006) Predictors of Condom Use Self-Efficacy in an Ethnically Diverse University Sample. Archives of Sexual Behavior, 35, 313-326.

[20] Carmack, C., Lewis, R.K. and Roncancio, A. (2015) Get the Message: Targeting Beliefs to Develop Risk Reduction Intervention Messages for African American Adolescents. American Journal of Community Psychology, 55, 396-410.

https://doi.org/10.1007/s10464-015-9719-x

[21] Guan, M., Coles, V.B., Samp, J.A., Sales, J.M., DiClemente, R.J. and Monahan, J.L. (2016) Incorporating Communication into the Theory of Planned Behavior to Predict Condom Use among African American Women. Journal of Health Communication, 21, 1046-1054. https://doi.org/10.1080/10810730.2016.1204383

[22] Sharts-Hopko, N.C. (2001) Focus Group Methodology: When and Why? Journal of the Association of Nurses in AIDS Care, 12, 89-91. https://doi.org/10.1016/S1055-3290(06)60220-3

[23] Braun, V. and Clarke, V. (2006) Using Thematic Analysis in Psychology. Qualitative Research in Psychology, 3, 77-101. https://doi.org/10.1191/1478088706qp063oa

[24] Gale, N.K., Heath, G., Cameron, E., Rashid, S. and Redwood, S. (2013) Using the Framework Method for the Analysis of Qualitative Data in Multi-Disciplinary Health Research. BMC Medical Research Methodology, 13, 117.

https://doi.org/10.1186/1471-2288-13-117

[25] Carmack, C., Lewis, R.K., Roncancio, A.M. and Gerecht, L.T. (2016) Guidelines for Construct Measurement Yielding Unexpected Higher-Order Constructs: An Application for the Theory of Planned Behavior Applied to Condom Use. American Journal of Psychology and Behavioral Sciences, 3, 25-33.

[26] Brawner, B.M., Jemmott, L.S., Wingood, G., Reason, J. and Mack, N. (2018) HIV/STI Prevention among Heterosexually Active Black Adolescents with Mental Illnesses: Focus Group Findings for Intervention Development. Journal of the Association of Nurses in AIDS Care, 29, 30-44. https://doi.org/10.1016/j.jana.2017.09.008

[27] Mercer, C.H., Aicken, C.R.H., Tanton, C. Estcourt, C.S., Brook, M.G., Keane, F. and Cassell, J.A. (2013) Serial Monogamy and Biologic Concurrency: Measurement of the Gaps between Sexual Partners to Inform Targeted Strategies. American Journal of Epidemiology, 178, 249-259. https://doi.org/10.1093/aje/kws467

[28] Sun, W.H., Wong, C.K.H. and Wong, W.C.W. (2017) A Peer-Led Social Media-Delivered Safer Sex Intervention for Chinese College Students: Randomized Controlled Trial. Journal of Medical Internet Research, 19, e284.

https://doi.org/10.2196/jmir.7403 